\title{
Isotope of amino acids reveals multiple sources of nitrogen in an intricate tropical mangrove food web
}

\author{
BENOIT THIBODEAU ${ }^{1}$, LAURA E AGUSTO ${ }^{2}$, LAETITIA \\ ALLAIS $^{1}$, WING K SO ${ }^{1}$, DAVID M BAKER ${ }^{2}$, STEFANO \\ $\mathrm{CANNICCI}^{2}$
}

${ }^{1}$ Department of Earth Sciences and Swire Institute of Marine

Science, The University of Hong Kong

${ }^{2}$ School of Biological Sciences and Swire Institute of Marine

Science, The University of Hong Kong

Despite recent advances in developing robust empirical methods to assess the feeding behaviour of an organism, the precise determination of the trophic niche of a species remains a challenge, especially for omnivores. For this reason, the determination of a robust food web has proven difficult in mangroves. In fact, omnivorous crabs are the most abundant macrofaunal group in these forests and, although their crucial role in the food chain has been demonstrated, it is still difficult to ascertain their tropic niche.

Here, we sampled up to 6 specimens per 32 unique species, within a single mangrove forest of Hong Kong and analysed the nitrogen and carbon isotopic composition of amino acids. We will highlight how nitrogen stable isotope values allow the identification of different dietary nitrogen sources in this mangrove food web and especially in omnivorous organisms. We will present a detailled food web and discuss its ecological implications.

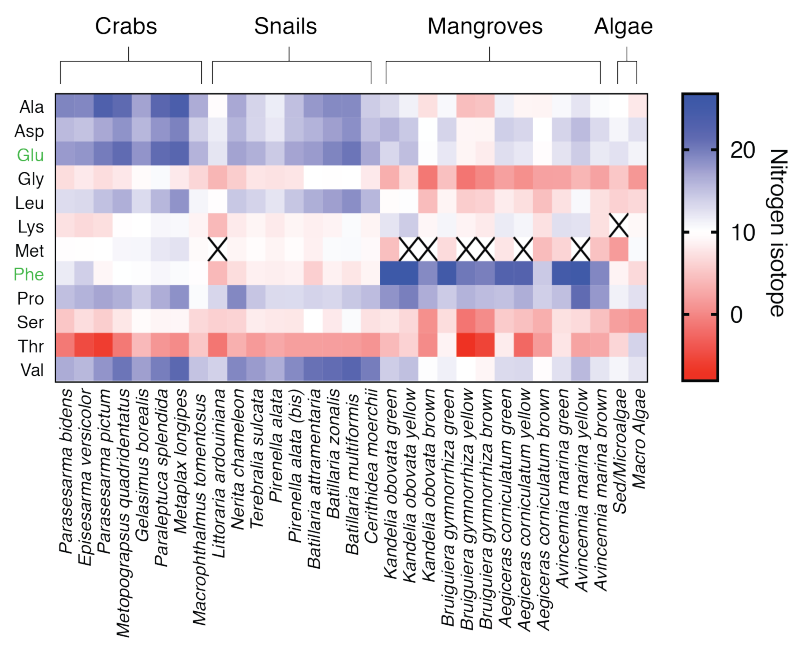

